\title{
Naloxone reduces pressing for intracranial stimulation of sites in the periaqueductal gray area, accumbens nucleus, substantia nigra, and lateral hypothalamus
}

\author{
JUNE M. STAPLETON, VICKI J. MERRIMAN, CONSTANCE L. COOGLE \\ STEVEN D. GELBARD, and LARRY D. REID \\ Rensselaer Polytechnic Institute, Troy, New York 12181
}

\begin{abstract}
Albino rats were implanted with bipolar electrodes aimed for the periaqueductal gray area, accumbens nucleus, substantia nigra, or lateral hypothalamus and trained to press for intracranial stimulation (ICS) of $60-\mathrm{Hz}$ sine waves, . $3 \mathrm{sec}$ duration, always less than $85 \mu \mathrm{A}$, rms. After stabilization of press rates, the rats were tested under morphine, naloxone, or placebo. Morphine sulfate $(10 \mathrm{mg} / \mathrm{kg}, \mathrm{SC})$, with testing $3 \mathrm{~h}$ after injection, produced an increase in press rates at all sites tested. Naloxone hydrochloride $(10 \mathrm{mg} / \mathrm{kg}, \mathrm{SC})$, given immediately before testing, produced reliable reductions in press rates in a $50-60-\mathrm{min}$ test at all four sites. The same dose of naloxone, given $15 \mathrm{~min}$ before a 3-min test, produced a small, but reliable, reduction in pressing for ICS of the periaqueductal gray area and had no reliable effect on pressing for ICS of the accumbens nucleus or lateral hypothalamus. These results suggest that endorphin systems play a modulatory role in pressing for ICS.
\end{abstract}

There is a satisfying concordance among the results of the various laboratories working with opioids and intracranial self-stimulation (for a recent review, see Esposito \& Kornetsky, 1978), except with respect to the effects of naloxone. Tests with naloxone are important from a number of perspectives. Naloxone is considered to be a specific antagonist of morphine (Jaffe \& Martin, 1975). Therefore, when a morphinelike effect is blocked by naloxone, such a test provides evidence that the effect is a specific opioid effect (Hayes, Price, \& Dubner, 1977). With the discovery that there are endogenous morphine-like systems in the brain (for a recent review, see Goldstein \& Cox, 1978), the effects of naloxone take on new significance. There is the expectation that an effect produced by naloxone in opioid-naive animals reflects modification of endorphin activity (Goldstein, 1978; Hayes et al., 1977).

Naloxone has produced a variety of effects on intracranial self-stimulation. Naloxone has (a) blocked opioid-induced facilitation of self-stimulation, producing rates similar to placebo controls (Bozarth \& Reid, 1977); (b) blocked opioid-induced facilitation of pressing, but lowered the rate of pressing to below

This work was supported by Grant DA02044 from the National Institute on Drug Abuse. The expert technical assistance of Marcia D. Lind is gratefully acknowledged. Naloxone hydrochloride courtesy of Endo Laboratories. control rates (Pert, 1975); (c) lowered the rate of pressing by as much as $60 \%$ in opioid-naive subjects (Belluzzi \& Stein, 1977); and (d) failed to produce a reliable shift in pressing in opioid-naive subjects (Goldstein \& Malick, 1977; Holtzman, 1976; Van der Kooy, LePiane, \& Phillips, 1977). From their results, Belluzzi and Stein (1977) concluded that endorphins were important to intracranial reward, whereas Van der Kooy et al. (1977) concluded they had no relevance to intracranial reward. Differences in electrode placements and in procedures may account for these differences in results and conclusions.

A major difference between the procedures yielding marked lowering of press rates in opioid-naive rats under naloxone and those procedures that failed to yield marked reductions is the site of intracranial stimulation (ICS). Belluzzi and Stein (1977) had rats pressing for ICS of the periaqueductal gray area, while Van der Kooy et al. (1977) had rats pressing for ICS of the lateral hypothalamus and caudate nucleus. The purpose of these experiments was to see whether the variable of sites of ICS was the critical difference resulting in the differential effects achieved in various experiments. Belluzzi and Stein (1977) suggested that rats with electrodes in regions having a high density of opiate receptors would show reductions in rates of pressing for ICS under naloxone. We chose to test, in this series of experiments, three regions high in enkephalins, the periaqueductal gray 
area, accumbens nucleus, and substantia nigra (Frederickson, 1977), in addition to the lateral hypothalamic site commonly used for self-stimulation experiments.

As our research progressed, it became clear that site of ICS was not the only salient variable (Stein \& Belluzzi, Note 1) and, therefore, other procedural differences were explored. It was found that the duration of the self-stimulation test was a salient variable. Since the experiments reported here were being done concurrently, one experiment could not be modified in light of results from another experiment.

\section{GENERAL METHOD}

\section{Subjects}

The subjects of these procedures were adult, male rats (Taconic Farms, Sprague-Dawley derived), weighing between 225 and $375 \mathrm{~g}$ at the beginning of the procedures. With the exception of the lateral hypothalamic subjects of Experiment 3, no animal had received opioids prior to first injection with naloxone. Each was fixed, using a standard stereotaxic procedure, with one or two chronically indwelling bipolar electrodes. The electrodes (Plastic Products, 303/2, .25 mm strand diameter) were stainless steel and insulated except at the cross section of the stimulating tips. The stimulating tips of a single bipolar electrode were separated only by the width of their insulation.

Surgery was performed under sodium pentobarbital anesthesia $(45 \mathrm{mg} / \mathrm{kg})$ with atropine sulfate as an adjunct. Following surgery, penicillin was usually administered. A subject's head was held in the stereotaxic instrument so that bregma and lambda were in the same horizontal plane, perpendicular to the shaft of the electrode. Stereotaxic coordinates for the four sites of ICS used were (a) lateral hypothalamus (LH) $3.3 \mathrm{~mm}$ posterior to bregma, $1.5 \mathrm{~mm}$ lateral to the midline, $8.2 \mathrm{~mm}$ below the surface of the skull; (b) periaqueductal gray area (PAG): $.5 \mathrm{~mm}$ posterior to the interaural plane, $.5 \mathrm{~mm}$ lateral to the midline, $6.2 \mathrm{~mm}$ below the surface of the skull; (c) accumbens nucleus (ACC): $9.4 \mathrm{~mm}$ anterior to the interaural plane, $1.2 \mathrm{~mm}$ lateral to the midline, $5.7 \mathrm{~mm}$ below the surface of the skull; and (d) substantia nigra (SN): $2.6 \mathrm{~mm}$ anterior to the interaural plane, $2.2 \mathrm{~mm}$ lateral to the midline, $7.3 \mathrm{~mm}$ below the surface of the skull.

From the time of surgery to completion of testing, the rats lived individually in standard cages with food and water always available. After completion of behavioral testing, the animals were sacrificed using an overdose of sodium pentobarbital and intracardially perfused with physiological saline followed by $10 \%$ Formalin solution. For verification of electrode placement, $90 \mu$ frozen sections of brain were treated as photographic negatives to make enlarged $(10 \times)$ photographs of brain sections.

\section{Apparatus}

The subjects were tested for pressing rates in one of five nearly identical clear plastic chambers $(24 \times 30 \times 35 \mathrm{~cm})$ housed within a lighted, sound-attenuating box. The chamber contained a $2.5 \times 4.0 \mathrm{~cm}$ lever mounted $7.5 \mathrm{~cm}$ above the floor. One leverpress yielded a single train of ICS of $60-\mathrm{Hz}$ sine waves, $.3 \mathrm{sec}$ duration, of varying intensities (24 to $84 \mu \mathrm{A}$, rms). ICS was delivered by way of light, flexible leads attached to an overhead commutator to allow the rat unhampered movement. Press rates were automatically recorded during each 3-min trial or during each 5-min period of a 50- to 60-min test.

Stimulation-produced analgesia was tested using a modification of the procedure of D'Amour and Smith (1941). The apparatus used was a heated coil mounted on a wooden block. Temperature was maintained between $68^{\circ}$ and $71^{\circ} \mathrm{C}$. The rat's tail was placed on the coil, and latency to tail flick was measured before and after ICS. ICS used in tail-flick procedures was $60-\mathrm{Hz}$ sine waves, $.25 \mathrm{sec}$ on, $.25 \mathrm{sec}$ off, of varying durations and intensities, with a maximum of $25 \mathrm{sec}$ of $70 \mu \mathrm{A}$, rms.

\section{Procedure}

After at least 5 days for recovery from surgery, rats were trained to press for ICS and subsequently tested daily for pressing for ICS. During the initial periods with ICS, an individual current intensity was selected for each site of each rat, and that intensity was used throughout the remaining self-stimulation tests.

After selection of ICS intensities, the subjects were tested daily (at the same time of day for each series of tests and always in the same chamber) until press rates stabilized. After press rates had stabilized (at least 7 days), daily injections were begun. The injection was a naloxone or morphine solution, or a placebo, physiological saline, the carrier of morphine and naloxone. All injections were in $1 \mathrm{ml} / \mathrm{kg}$ volume.

Since there is a possibility for addictive agents to affect selfstimulation rates on days after their administration, i.e., have carryover effects, rates of pressing after morphine or naloxone were compared with rates of pressing of the immediately preceding daily sessions after saline injections.

\section{EXPERIMENT 1}

Experiment 1 assessed the effects of naloxone and morphine on pressing for ICS of sites in the periaqueductal gray area (PAG), the area studied by Belluzzi and Stein (1977). Some of the subjects also had an electrode for stimulating the lateral hypothalamic area $(\mathrm{LH})$, an area studied by Van der Kooy et al. (1977). Our original intention was to compare changes in press rates under naloxone for the two sites using the same subject. Our preliminary inspections of the data suggested, however, that naloxone was not reducing PAG self-stimulation as observed by Belluzzi and Stein. Consequently, we talked by telephone with them (Stein \& Belluzzi, Note 1), and it was concluded that our use of short durations of testing (daily tests of $3 \mathrm{~min}$, starting $15 \mathrm{~min}$ after naloxone injection) compared to their long duration of testing (daily tests of $1 \mathrm{~h} 15 \mathrm{~min}$, starting immediately after injection) might account for our differences in outcomes. Consequently, tests using longer durations were instituted.

\section{Method}

Eight experimentally naive rats were selected from a pool of 14 rats implanted with electrodes aimed for the PAG and the contralateral LH. Subjects were selected on the basis of PAG pressing regardless of $\mathrm{LH}$ pressing. All 8 rats self-stimulated at the PAG site, and 5 of them also self-stimulated at the LH site.

After pressing rates had stabilized, daily injections were begun. The initial series of daily injections included 3 days of physiological saline, 3 days of naloxone hydrochloride $(10 \mathrm{mg} / \mathrm{kg})$, 3 days of morphine sulfate $(10 \mathrm{mg} / \mathrm{kg})$, and 3 days of saline. Saline and naloxone were given intraperitoneally (IP) $15 \mathrm{~min}$ before testing, while morphine was given subcutaneously (SC) $3 \mathrm{~h}$ before testing. During this injection series, each rat was tested daily for $3 \mathrm{~min}$ at the PAG site, and this test was followed immediately by $3 \mathrm{~min}$ at the LH site if the rat self-stimulated at both sites. 
Following this series of 3-min tests, 6 rats were tested daily for ICS of the PAG alone in 1-h sessions. After at least 3 days to adjust to the new testing regimen, each rat was injected, SC, immediately prior to testing each day. The 1 st day, all rats received physiological saline, the next 2 days, they received naloxone hydrochloride $(10 \mathrm{mg} / \mathrm{kg}, \mathrm{SC})$, and on a final day, they received saline.

At the conclusion of ICS tests, the rats were allowed at least 8 days of no treatment prior to testing for stimulation-produced analgesia. At least three measures of tail-flick latency were taken before ICS. A measure was taken immediately after a sequence of ICS. If no tail flick occurred, the trial was terminated after $7 \mathrm{sec}$ and a maximum score of 7.0 was recorded. If tail-flick latency after ICS was similar to latency before ICS, testing continued with higher intensities of ICS.

\section{Results and Discussion}

The scores from tests with PAG stimulation during the series of 3-min tests were submitted to a 1 by 4 analysis of variance (ANOVA), having repeated measures with factors of one group and four drug treatments. The scores were the mean for each subject under predrug placebo, naloxone, morphine, and postdrug placebo. The results indicated a statistically significant effect for the factor of drug treatments $[\mathrm{F}(3,31)=6.38, \mathrm{p}<.01]$. The mean press rate across the first 3 days of placebo was 48.9 presses/ min, and across the last 3 days of placebo was $48.7 \mathrm{presses} / \mathrm{min}$. The mean under naloxone was $45.3 \mathrm{presses} / \mathrm{min}$. A comparison, using a t test for correlated measures, between pressing of predrug placebo and naloxone scores yielded a $\mathrm{t}(7)=3.42$, $\mathrm{p}<.02$. The difference between means (about 3 presses /min, or about an $8 \%$ decrease), although small, is statistically significant. The mean press rate of the tests under morphine was 57.3 presses/min, about a $17 \%$ increase compared with scores under placebo. Comparing the morphine scores to predrug placebo yielded a $\mathrm{t}(7)=2.21, \mathrm{p}<.06$, compared to postdrug placebo $\mathrm{t}(7)=3.05, \mathrm{p}<.02$. In summary, naloxone produced a slight (about $8 \%$ ), but statistically significant, decrease in pressing, while morphine produced an increase in pressing for PAG stimulation during brief tests at some time after drug administration.

Scores from the five subjects who were also tested for lateral hypothalamic ICS in 3-min sessions across the injection series indicated that naloxone had no statistically significant effect on pressing rates for hypothalamic ICS $[\mathrm{t}(4)=.52, \mathrm{p}>.60$ ]. Morphine produced its characteristic increment in pressing for hypothalamic stimulation, but with these subjects the increment was not so great that the difference met standards of statistical significance using predrug placebo as a standard. A comparison between scores of the postdrug placebo and morphine did, however, yield a $\mathrm{t}(4)=2.78, \mathrm{p}<.05$, and indicated that morphine did produce its typical $20 \%$ increase in pressing for hypothalamic ICS. From previous research
(Adams, Lorens, \& Mitchell, 1972; Bush, Bush, Miller, \& Reid, 1976; Reid \& Bozarth, 1978), it is well established that morphine under these circumstances of testing will lead to a significant increment in pressing for LH ICS but that all subjects do not show the increment. In one sample, for example, 55 of 65 hypothalamic subjects showed substantial increments in pressing for hypothalamic ICS, yielding a $p$ value $<.00001$ to support the conclusion that morphine leads to increments in pressing (Reid \& Bozarth, 1978). These results indicate that, given the variability inherent in either site of ICS or in drug responses, a larger number of subjects than is typical in studies of ICS and drugs is probably necessary before firm conclusions are drawn.

During 1-h tests of pressing for PAG stimulation, press rates were recorded every $5 \mathrm{~min}$, yielding 12 scores/day for each rat. The scores of the 2 naloxone days were averaged for each 5-min period. Figure 1 presents mean difference scores obtained by subtracting from the mean of the two naloxone scores for each 5-min period the predrug placebo score for the corresponding 5-min period. These 12 means under naloxone, together with the comparable scores of the predrug and postdrug placebo days were submitted to a 3 by 12 ANOVA, having repeated measures with factors of 3 drug conditions (predrug placebo, naloxone, postdrug placebo) and 12 trials (12 5-min periods of a 1-h test). The results of this ANOVA indicated statistically significant effects for the factor of drug treatments $[\mathrm{F}(2,10)=5.13$, $p<.05]$ and for the factor of trials $[F(11,55)=$

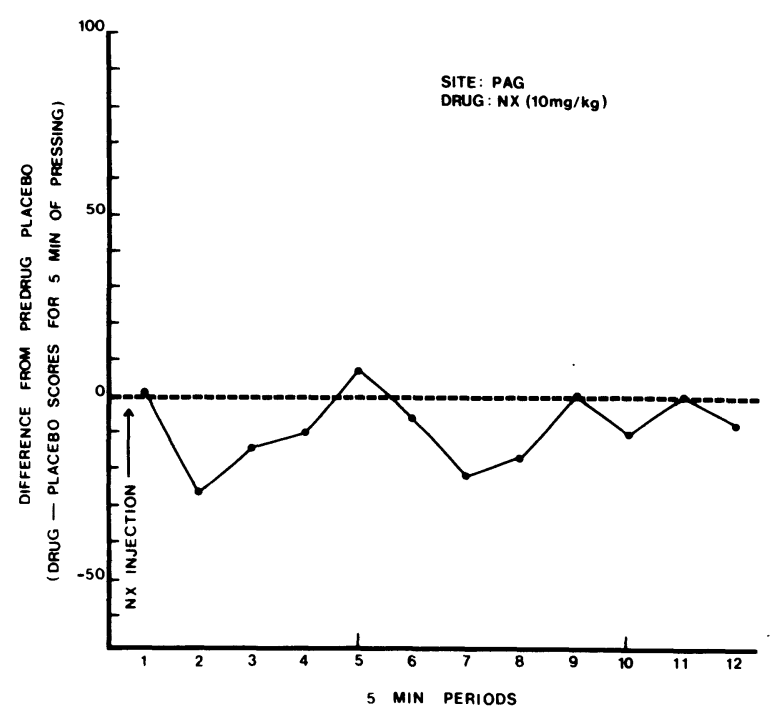

Figure 1. Mean difference scores (presses/5-min period) derived by subtracting mean placebo from mean naloxone scores for the corresponding 5-min period of pressing for ICS of the PAG. Negative scores represent decreases in pressing below placebo levels. $\mathrm{NX}$, naloxone hydrochloride (10 $\mathrm{mg} / \mathrm{kg}, \mathrm{SC})$. 
$3.27, \mathrm{p}<.01]$. The Drug Condition by Trials interaction was not a reliable source of variance $[F(22,110)$ $<1]$. The mean of the naloxone scores averaged across all 12 trials on both days is $35.1 \mathrm{presses} / \mathrm{min}$ compared with the preceding placebo mean of $38.5 \mathrm{presses} / \mathrm{min}$, a small $(8.8 \%)$, but reliable, decrease $[\mathrm{t}(5)=4.29, \mathrm{p}<.01]$. The significant trials effect presumably reflects the decline in ICS press rates usually seen during a test of this length, and the lack of a significant interaction suggests that this "fatigue effect" is similar under the influence of naloxone or placebo.

On tests for stimulation-produced analgesia, mean tail flick latency for all eight rats prior to PAG stimulation was $2.6 \mathrm{sec}$ and after stimulation, $5.4 \mathrm{sec}$, a statistically significant difference on a $t$ test for correlated measures $[t(7)=4.02, p<.01]$, confirming that in general these electrode placements were in a region where electrical stimulation can produce analgesia. Histological analysis indicated that two of the eight rats had doubtful PAG electrode placements with the stimulation field lateral or ventral to the PAG. There were slight differences in electrode placements within the PAG, but there were no apparent differential effects due to electrode site. All data analyses were repeated using only the data of the subjects with clear PAG placements. Similar results were obtained, leading to the same conclusions.

In general, the effects of naloxone on pressing for PAG stimulation were small; nevertheless, naloxone did reliably reduce pressing for PAG stimulation, thereby confirming Belluzzi and Stein's (1977) findings, and did not reliably reduce pressing for $\mathrm{LH}$ stimulation, thereby confirming Van der Kooy et al.'s (1977) findings. Such a result is satisfying because it makes the results concordant across laboratories and suggests that there may be specific sites of ICS that are naloxone sensitive and that might be uniquely involved with an endorphinergic system. Further study and data collection, however, put these results in a different light.

\section{EXPERIMENT 2}

This experiment is similar to Experiment 1, except that the sites of ICS were in the accumbens nucleus (ACC).

\footnotetext{
Method

Seven experimentally naive subjects were selected from a pool of 14 rats on the basis of pressing for ICS of the ACC. Five of these subjects also self-stimulated at a contralateral electrode aimed for the lateral hypothalamic area (LH).

After press rates had stabilized, each rat was tested daily for 3 min at the ACC site, and this test was followed immediately by $3 \mathrm{~min}$ at the LH site if the rat self-stimulated at both sites. An injection of naloxone hydrochloride $(10 \mathrm{mg} / \mathrm{kg})$ or physiological
}

saline $(1 \mathrm{ml} / \mathrm{kg})$ was given IP $15 \mathrm{~min}$ prior to testing each day. All rats received 3 days of saline trials before a series of naloxone trials.

Following this series of 3-min tests, rats were tested daily for pressing for ICS of the ACC alone in 1-h sessions. After at least 3 days to adjust to the new testing regimen, the following series of daily injections was begun: 3 days of saline, 2 days of naloxone, 3 days of saline, 2 days of naloxone, 3 days of saline, 5 days of morphine sulfate $(10 \mathrm{mg} / \mathrm{kg})$, and 3 days of saline. Saline and naloxone were given SC immediately before testing, while morphine was given SC $3 \mathrm{~h}$ prior to testing. After these tests, there was a final session during which the intensity of ICS was turned to zero after the first $10 \mathrm{~min}$, and press rates were observed across $50 \mathrm{~min}$ of extinction. After at least 7 days of no treatment, an attempt was made to test for stimulation-produced analgesia.

\section{Results and Discussion}

Seven rats received 3 days of 3 -min tests under naloxone, while four of these continued daily 3-min tests for 15 days under naloxone. For all seven rats, the mean press rate at the ACC for 3 days of placebo treatment was 23.9 presses/min, not reliably different from the mean of 25.4 presses/min for the first 3 days of naloxone $[t(6)=0.58, p>.50]$. For four subjects, the mean of 15 consecutive days under naloxone ( $28.1 \mathrm{presses} / \mathrm{min})$ was not reliably different from the mean of the preceding 3 days of placebo (20.7 presses $/ \mathrm{min})[\mathrm{t}(3)=2.20, \mathrm{p}>.10]$. Particularly since press rates have a tendency to increase across days without any manipulation (Bush et al., 1976), it appears that naloxone had little effect on pressing for ACC ICS when the naloxone was given $15 \mathrm{~min}$ before a 3-min test of ACC self-stimulation.

In 3-min tests at the LH electrode, the mean of the first 3 days of naloxone for all five rats that pressed at this site was 74.5 presses/min compared with $80.3 \mathrm{presses} / \mathrm{min}$ for the preceding 3 days of placebo, a $7.2 \%$ decrease, not statistically significant $[\mathrm{t}(4)=$ $1.09, \mathrm{p}>.30]$. Of the four rats tested for 15 days under naloxone, two pressed at the LH site. For these two rats, the mean across 15 days of naloxone tests at the LH was 95.3 presses/min compared with 89.4 presses/min for the preceding 3 days of placebo, a $6.7 \%$ increase, also not statistically significant $[\mathrm{t}(1)=1.12, \mathrm{p}>.40]$.

The results of 1 -h tests assessing the effects of naloxone and morphine on ACC self-stimulation are summarized in Figure 2. Using a t test for correlated measures, each naloxone block is reliably lower than the placebo block preceding $[\operatorname{ts}(6)=3.32,3.15$, ps $<.02]$. Comparing the morphine block with its preceding placebo block yields a $t(6)=2.22$, p $<.08$. During these tests, press rates were recorded every $5 \mathrm{~min}$, yielding 12 scores/day for each rat. The scores of consecutive days of the same drug treatment were averaged for each 5-min period for each drug condition. The means for each 5 -min period for each drug condition were submitted to a 7 by 12 ANOVA having repeated measures with factors of 7 drug con- 
SITE : ACC

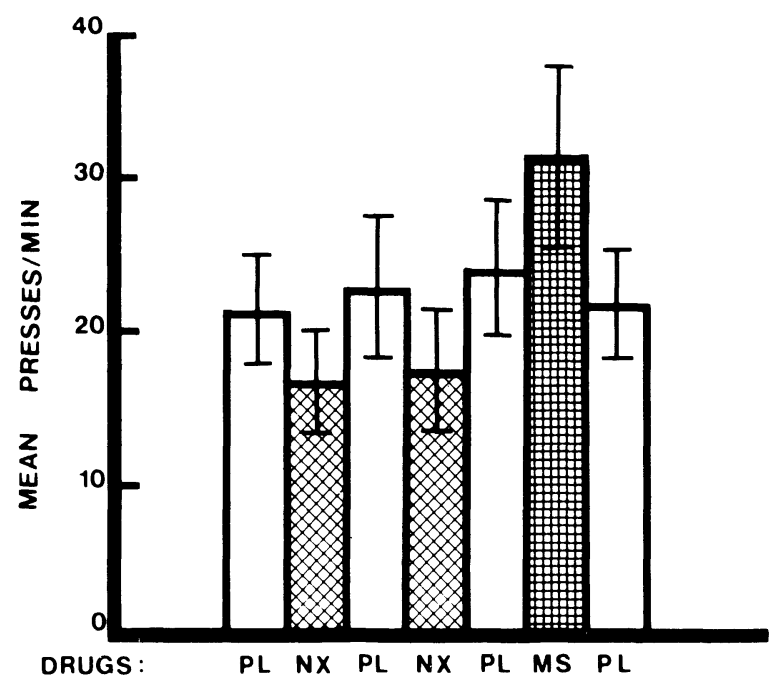

Figure 2. Mean presses/min \pm SEM. at the $A C C$ averaged across 12 -min periods and across consecutive days of the same drug treatment. $\mathrm{NX}$, naloxone hydrochloride $(10 \mathrm{mg} / \mathrm{kg}, \mathrm{SC})$; MS, morphine sulfate $(10 \mathrm{mg} / \mathrm{kg}, \mathrm{SC})$ given $3 \mathrm{~h}$ prior; PL, placebo, physiological saline $(1 \mathrm{ml} / \mathbf{k g}, \mathrm{SC})$.

ditions (4 separate blocks of placebo, 2 separate blocks of naloxone, and 1 block of morphine treatment) and 12 trials (12 5-min periods). The results of this ANOVA indicated statistically significant effects for the factor of drug conditions $[F(6,36)$ $=9.45, \mathrm{p}<.005]$ and for the factor of trials $[\mathrm{F}(11,66)$ $=21.46, \mathrm{p}<.005]$, and a significant Drug by Trial interaction $[\mathrm{F}(66,396)=1.86, \mathrm{p}<.005]$. An inspection of the graph of raw scores indicates that the interaction effect is due to initial trials in which pressing under morphine was considerably enhanced.

Figure 3 presents difference scores obtained by averaging the scores of the two naloxone blocks for each 5-min period and subtracting the mean of the two preceding placebo blocks; and for morphine by subtracting from the morphine score for each 5-min period the score of the preceding placebo block. During the test of pressing for ACC ICS of zero intensity, all rats essentially ceased pressing within 10 min after the current was turned to zero.

Tests for stimulation-produced analgesia proved impracticable with these subjects due to their low seizure thresholds. Stimulation parameters that might have been sufficient to induce analgesia precipitated seizures, and it was impossible to test for tailflick latency during the ensuing period of postictal excitability. Histological analysis indicated that all seven rats had electrode placements in the ACC, but that the sites were scattered throughout the ACC, including some sites having the anterior commissure within the probable stimulation field. No differential effects of these differences in electrode placements were apparent.
It is clear, in this circumstance, that results from brief tests with ICS, $15 \mathrm{~min}$ after injection, lead to different conclusions than do results from longer tests immediately after injection. From brief tests, it might be concluded that naloxone has no effect on pressing for ACC ICS, while from longer tests, it can be concluded that naloxone significantly reduces pressing.

\section{EXPERIMENT 3}

With these subjects and procedures, the effects of naloxone and morphine on pressing for ICS of the substantia nigra (SN) were tested.

\section{Method}

Nine experimentally naive rats were selected from a pool of 16 rats implanted with a single bipolar electrode aimed for the substantia nigra. They were tested daily for pressing for ICS in 55-min sessions. After press rates had stabilized, the following injection series was begun: 3 days of saline, 2 days of naloxone $(10 \mathrm{mg} / \mathrm{kg}), 4$ days of saline, 4 days of morphine sulfate $(10 \mathrm{mg} /$ $\mathrm{kg}$ ), and 3 days of saline. Saline and naloxone injections were given between the first and second 5-min periods of a 55-min session, while morphine was given $3 \mathrm{~h}$ prior to testing. All injections were given SC. After at least 10 days of no treatment, eight rats were tested for stimulation-produced analgesia. One rat received no test because his electrode became dislodged in the intervening period.

\section{Results and Discussion}

Scores for Periods 2 through 11 (5-min periods that are after drug administration for all treatment conditions) were averaged across consecutive days of the same drug treatment. These means were submitted

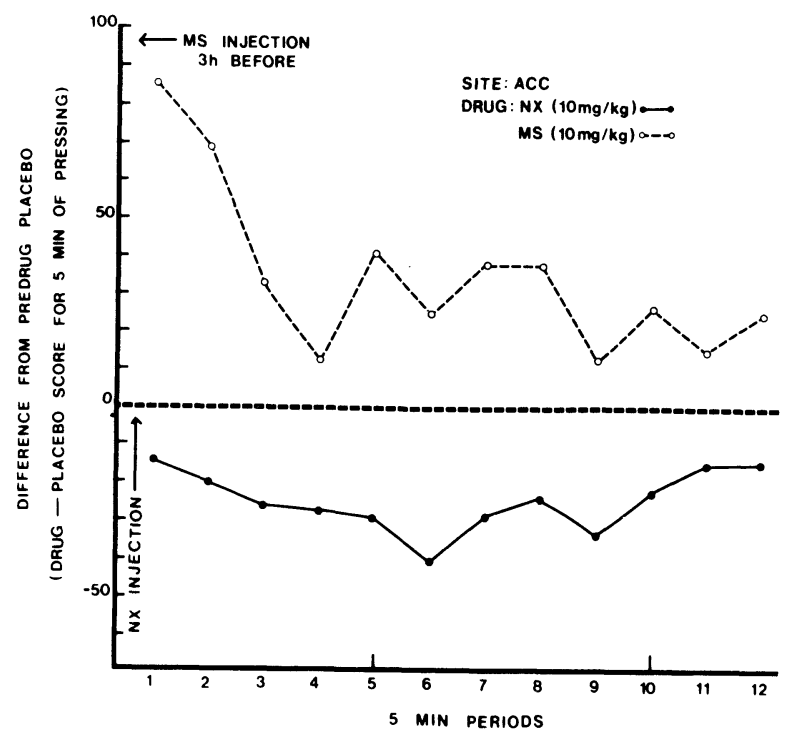

Figure 3. Mean difference scores (presses/5-min period) derived by subtracting mean placebo from mean naloxone or mean morphine scores for the corresponding 5-min period of pressing for ICS of the ACC. Positive scores indicate increases in pressing, negative scores decreases in pressing compared to placebo levels. $\mathrm{NX}$, naloxone hydrochloride $(10 \mathrm{mg} / \mathrm{kg}, \mathrm{SC}) ; \mathrm{MS}$, morphine sulfate (10 $\mathrm{mg} / \mathrm{kg}, \mathrm{SC}$ ) given $3 \mathrm{~h}$ prior. 


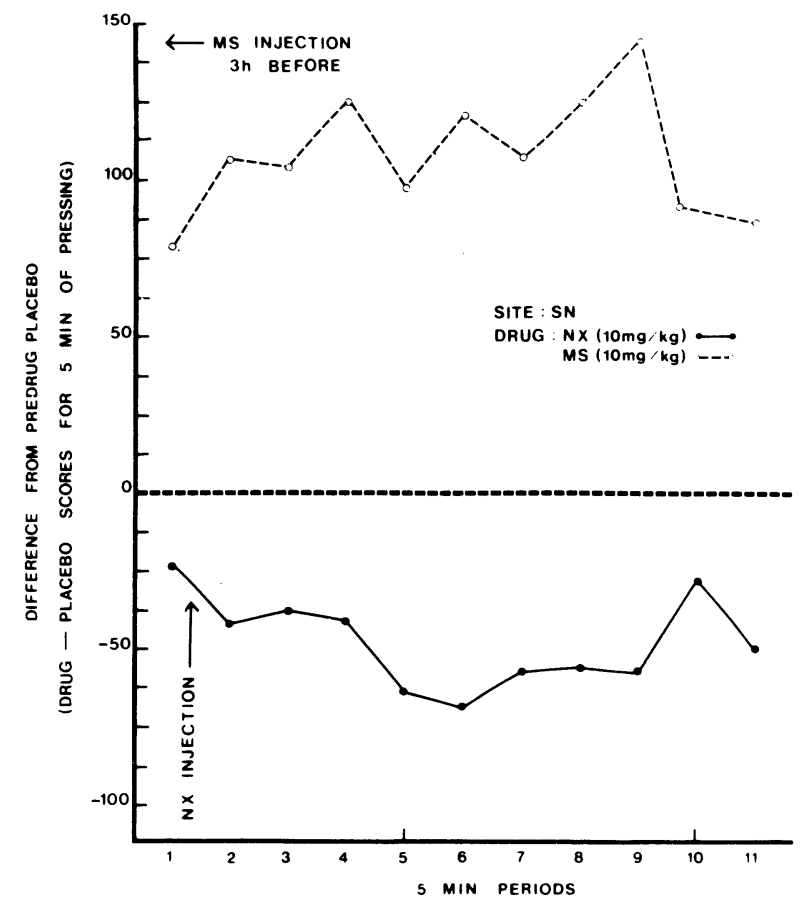

Figure 4. Mean difference scores (presses/5 min period) derived by subtracting mean placebo from mean naloxone or mean morphine scores for the corresponding 5-min period of pressing for ICS of the SN. Positive scores indicate increases in pressing, negative scores decreases in pressing. $\mathbf{N X}$, naloxone hydrochloride $(10 \mathrm{mg} / \mathrm{kg}, \mathrm{SC}) ; \mathrm{MS}$, morphine sulfate $(10 \mathrm{mg} / \mathrm{kg}, \mathrm{SC})$ given $3 \mathrm{~h}$ prior.

to a 5 by 10 ANOVA having repeated measures with factors of 5 drug-treatment conditions (naloxone, morphine, and 3 placebo blocks) and 10 trials (5-min periods). The results of this ANOVA indicated statistically significant effects for the factor of drug conditions $[\mathrm{F}(4,32)=9.58, \mathrm{p}<.001]$ and for the factor of trials $[\mathrm{F}(9,72)=7.05, \mathrm{p}<.001]$. The Drug by Trial interaction was not a reliable source of variance. The trials effect presumably reflects the usual decline in ICS press rates across a test of this length, and the lack of a significant interaction effect suggests that this "fatigue effect" is similar for placebo, naloxone, and morphine conditions.

The mean of the naloxone scores averaged across 105 -min periods is 40.2 presses/min compared with the preceding placebo mean of 50.3 presses $/ \mathrm{min}$, a $19.9 \%$ decrease, statistically significant on a t test for correlated measures $[\mathrm{t}(8)=2.84, \mathrm{p}<.03]$. For Period 1 , before injection, the naloxone mean of $55.9 \mathrm{presses} / \mathrm{min}$ was not reliably different from the placebo mean of 60.5 presses/min $[\mathrm{t}(8)=.92$, $\mathrm{p}>.25$ ]. The mean of the morphine scores was significantly higher than the mean of the preceding placebo block $[\mathrm{t}(8)=3.58, \mathrm{p}<.01]$. Figure 4 presents difference scores derived by subtracting from the mean of naloxone or morphine scores for each 5-min period the mean of the preceding placebo block for the corresponding 5-min period.

On tests for stimulation-produced analgesia, mean tail-flick latency for eight rats was $3.1 \mathrm{sec}$ before SN stimulation and $3.7 \mathrm{sec}$ after stimulation, not reliably different on $t$ test for correlated measures $[\mathrm{t}(7)=.68, \mathrm{p}>.50]$, indicating that in general these electrode placements were in a region where electrical stimulation does not produce analgesia. Histological analysis indicated that three of the nine rats had doubtful SN electrode placements with the stimulation field lateral or dorsal to the SN. There were also slight differences in electrode placements within the SN, but there were no apparent differential effects due to electrode site, and we could not discern the relationship described by Steiner and Ellman (Note 2). All data analyses were repeated using only the data of the subjects with clear SN placements. Similar results were obtained, leading to the same conclusions.

In summary, the results indicate that the substantia nigra is a region where morphine can facilitate and naloxone can suppress pressing for ICS. These effects occur at sites where stimulation does not produce analgesia.

\section{EXPERIMENT 4}

Experiments 1 and 2 included some tests of the effects of naloxone on pressing for ICS of the lateral hypothalamus ( $\mathrm{LH})$ in brief, 3-min tests. This experiment assessed the effects of naloxone $(10 \mathrm{mg}$ / $\mathrm{kg}$ ) on pressing for LH ICS in tests of longer duration, $55 \mathrm{~min}$.

\section{Method}

The subjects were six rats that had served as subjects in a previous study (Lind, Stapleton, Merriman, \& Reid, Note 3). Each had been implanted with a single LH electrode and had received several injections of small doses of morphine sulfate (less than $20 \mathrm{mg} / \mathrm{kg}$ total), at least 15 days before these tests.

Daily ICS tests were conducted as described for previous experiments, with all injections given SC between the first and second 5-min period of a 55-min test. After stabilization, the injection series was: 3 days of saline, 2 days of naloxone hydrochloride $(10 \mathrm{mg} / \mathrm{kg}), 3$ days of saline, 2 days of naloxone, and 3 days of saline.

\section{Results and Discussion}

Figure 5 presents mean press rates for each block of 3 days of placebo or 2 days of naloxone injections, averaged across Periods 2 through 11, that is, from 0 to $50 \mathrm{~min}$ after injection. Using a t test for correlated measures to compare each naloxone block with its preceding placebo block yields $\operatorname{ts}(6)=3.66$, 3.08 , ps $<.02, .10$, respectively. The mean of the naloxone scores averaged across 10 trials and both blocks is 36.3 presses/min compared with 46.8 presses/ min for the mean of the preceding placebo blocks, a decrease of $\mathbf{2 2 . 5 \%}$. For Period 1, before injection, 


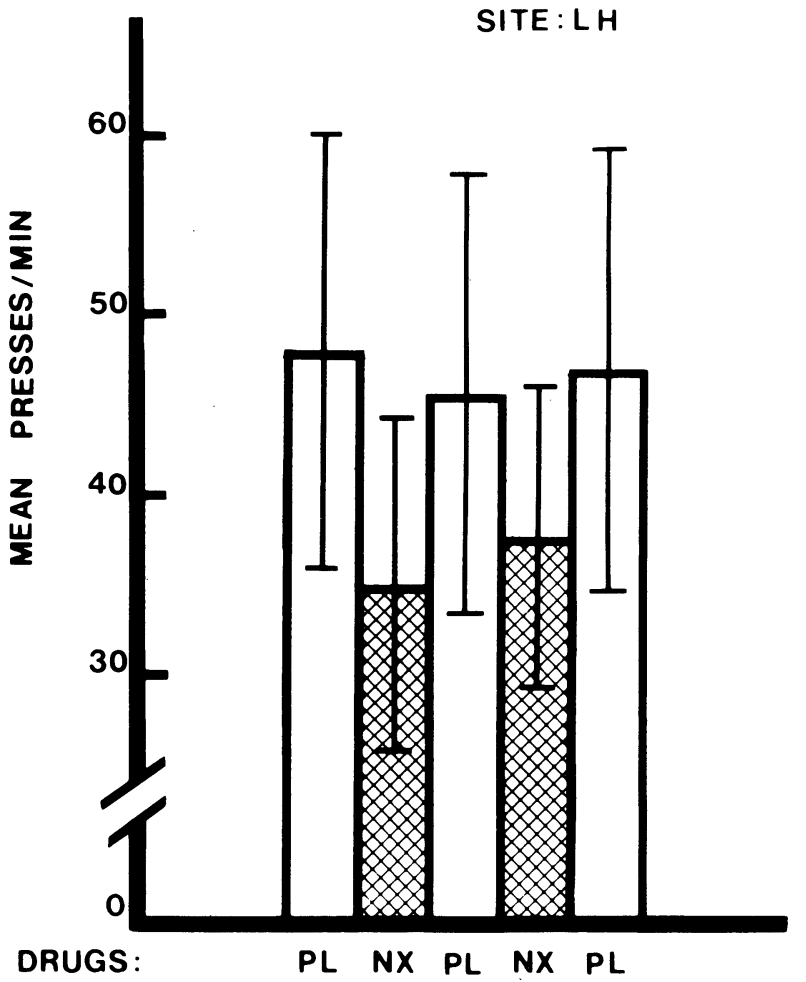

Figure 5. Mean presses/min \pm SEM. at the $\mathbf{L H}$ across 10 -min periods after injection and across consecutive days of the same drug treatment. $\mathrm{NX}$, naloxone hydrochloride $(10 \mathrm{mg} / \mathrm{kg}, \mathrm{SC})$; PL: placebo, physiological saline (1 ml/kg, SC).

the naloxone mean of $61.8 \mathrm{presses} / \mathrm{min}$ is not reliably different from the placebo mean of 61.5 presses $/ \mathrm{min}$ $[\mathrm{t}(5)=.12, \mathrm{p}>.90]$.

Figure 6 presents difference scores derived by averaging the scores of the two naloxone blocks for each 5-min period and subtacting the mean of the two preceding placebo blocks for the corresponding 5 -min period. The means for each 5-min period for each block were submitted to a 5 by 10 ANOVA having repeated measures with factors of 5 drug treatment conditions ( 2 naloxone and 3 placebo) and 10 trials (5-min periods). The results of this ANOVA indicated reliable effects for the factor of drug treatment condition $[F(4,20)=6.29, p<.005]$ and for the factor of trials $[\mathrm{F}(9,45)=8.95, \mathrm{p}<.001]$. The Drug by Trial interaction was not a reliable source of variance $[F(36,180)=1.01, p>.40]$.

Histological analysis indicated that all electrodes were in the lateral hypothalamic area, stimulating the medial forebrain bundle or surrounding areas, including the zona incerta. There were no apparent differential effects due to differences in electrode placement. The demonstration of a clear reduction in pressing for LH ICS is at variance with the conclusion that was derived by Van der Kooy et al. (1977) and can be derived from the results of Experiments 1 and 2. The use of small numbers of subjects, of course, increases the chances of Type II errors. Brief tests, because of their brevity, also increase the chances for Type II errors. Naloxone may not be as effective with the initial period of self-stimulation as it is with subsequent periods of pressing, even though the drug was given at the same time before the test period. Tests specifically designed to test for this possibility need to be done.

\section{GENERAL DISCUSSION}

There are informal observations, in addition to the formal counts of barpresses, that are interesting. When subjects were pressing for ACC ICS, they often had overt seizures. When a seizure was observed, the measurement of pressing was suspended. We are not sure, however, that all instances of seizures were observed, since they were usually brief and seemingly had little effect on subsequent pressing. Drugs did not seem to alter the instances of overt seizures. In general, rats pressing for ACC ICS appeared to be more seizure-prone than subjects pressing for other ICS and, in some cases, a rat which had seizures while pressing for ACC ICS had no seizures when it was pressing for LH ICS.

It was necessary to use higher current intensities to sustain pressing for PAG ICS (mean $=45.9 \mu \mathrm{A}$, yielding $38.5 \mathrm{presses} / \mathrm{min}$ ) compared to pressing for LH ICS (mean $=26.7 \mu \mathrm{A}$, yielding 46.8 presses/ min). Pressing for LH ICS was easiest to train, was sustained at faster rates by lower current intensities, and was accompanied by the fewest side effects.

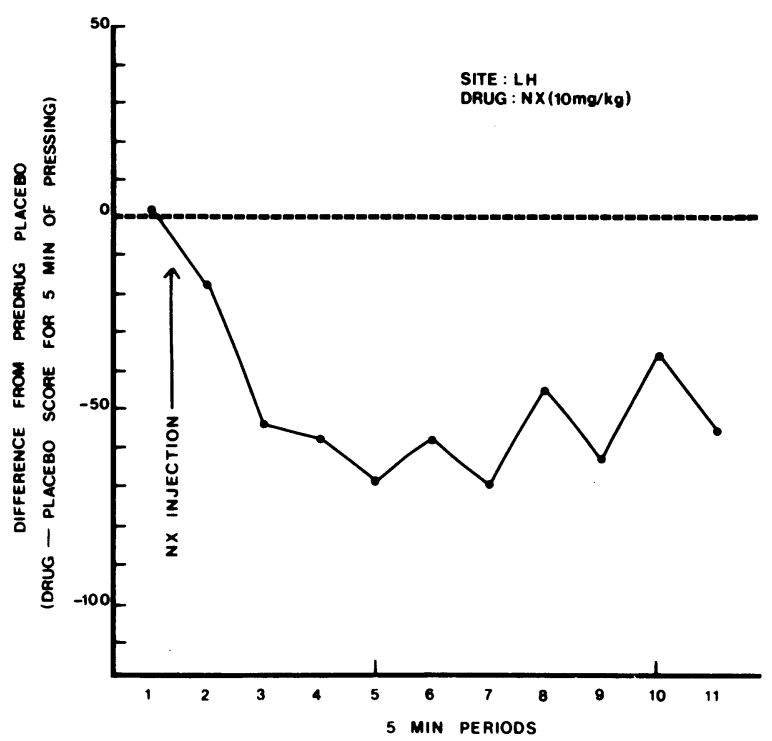

Figure 6. Mean difference scores (presses/5-min period) derived by subtracting mean placebo from mean naloxone scores for the corresponding 5-min period of pressing for ICS of the LH. Negative scores represent decreases in pressing. $\mathbf{N X}$, naloxone hydrochloride (10 mg/kg, SC). 
Pressing for SN ICS was also rapid and with few side effects.

Despite these differences in pressing for ICS across sites, morphine typically increases pressing about $20 \%$, and naloxone typically decreased pressing by less than $30 \%$. As with other studies using morphine and ICS, there were considerable individual differences in extent of the facilitation under morphine, with some subjects showing little facilitation and with others showing marked facilitation. There were also marked differences across subjects in reactivity to naloxone. There were no reliable correlations between extent of morphine's acceleration and naloxone's suppression within a group pressing for similar ICS under both conditions. The samples, however, are too small to draw any firm conclusions.

In some instances, press rates on the placebo day following naloxone administration were somewhat depressed, suggesting the possibility that some effects of naloxone may endure beyond the day of drug administration. A similar effect has been previously reported in tests of naloxone blockade of morphine facilitation of ICS (Bozarth \& Reid, 1977). This possibility bears further exploration.

Morphine reliably increases pressing for ICS (Esposito \& Kornetsky, 1978) and, furthermore, for ICS of many electrode sites. Morphine, at low doses or at higher doses some time after injection, increases pressing for ICS of frontal cingulate cortex (Lorens, 1976); accumbens nucleus (Experiment 2); lateral hypothalamic area, including medial forebrain bundle, zona incerta, Forel's fields, and areas known to be noradrenergic and dopaminergic (Adams, Lorens, \& Mitchell, 1972; Becker, 1977, Magnuson, 1977); the substantia nigra (Experiment 3); locus coeruleus area (Steiner \& Ellman, Note 2); the periaqueductal gray area (Liebman \& Segal, 1976; Experiment 1); and probably the amygdala (CruzMorales \& Reid, Note 4). Naloxone, $10 \mathrm{mg} / \mathrm{kg}$, and probably with lower doses (Belluzzi \& Stein, 1977; unpublished data of our laboratory), reliably decreases pressing for ICS of the periaqueductal gray area (Belluzzi \& Stein, 1977; Experiment 1), substantia nigra, lateral hypothalamic area, and accumbens nucleus (Experiments 2-4). This ubiquity of effects of morphine, and possibly naloxone, indicates that the drugs may have effects that transcend any one electrode site.

The mean amount of suppression under naloxone typically varied from $8 \%$ to about $30 \%$. In general, the amount of suppression was least with the PAG subjects. These subjects' pressing rates were very stable, and that allowed the relatively small mean reductions to emerge as reliable effects. The PAG was the general area for which Belluzzi and Stein (1977) reported large (about 50\%) reductions. It may be that the exact site of ICS within the general PAG area might account for the degree of reduction in pressing under naloxone. Only a comprehensive mapping study, varying sites across the general area, will give us the perspective necessary to make some general statements concerning the amount of reduction in pressing for PAG ICS under naloxone. Relatedly, with individual differences seen within each general area of ICS, it seems premature to compare amount of reductions across sites of ICS. In general, all of these areas are areas in which there are concentrations of endorphins, but those concentrations are not necessarily evenly distributed within an area (Kuhar, 1978).

The results presented here clearly demonstrate that naloxone does, indeed, reduce pressing for ICS, and the different conclusions drawn by Belluzzi and Stein (1977) and Van der Kooy et al. (1977) can be inspected in the light of new data. As mentioned, the reductions we observed were not as great as those reported by Belluzzi and Stein (1977) and the observed reductions were not similar to reductions seen when rats are extinguishing pressing for ICS. Also as mentioned, only further study will determine whether large reductions are rare and site specific. In general, naloxone does not abolish self-stimulation, but produces, on the average, rather small reductions in press rates. If we can assume that naloxone produces essentially complete blockade of endorphinergic systems, it is difficult to conclude that endorphinergic systems are critical to reward processes or mediate a critical component of the reward process. Endorphinergic processes may surely modify reward but do not seem to be critical to reward, at least intracranial reward.

A close inspection of the data of Van der Kooy et al. (1977) shows that they did get slight mean reductions in pressing for ICS with doses of $10 \mathrm{mg}$ / $\mathrm{kg}$ of naloxone and with greater doses. Furthermore, under naloxone the variance of press rates increased inordinately. In fact, ratios of the variance derived from their standard errors of means lead to the conclusion that naloxone reliably increased the variance of press rates. They concluded, however, based on not getting statistically significant reductions, that naloxone made no difference with respect to press rates except at the higher doses $(40 \mathrm{mg} / \mathrm{kg})$. They (Van der Kooy et al., 1977) summarized their conclusions by saying that there is "at least a partial independence of the opiate reinforcement system and the ICSS reinforcement system in the rat brain" (p. 984). And, "Regardless of the nature of the morphine-induced changes in ICSS, the present study has provided evidence against any important role for an endorphin-opiate receptor mechanism in the maintenance of ICS" (p. 985, italics added). Our data, demonstrating small but reliable reductions in press rates, support the first conclusion but lead us to question the second, stronger conclusion.

Van der Kooy et al. (1977) tested only nine rats across both caudate nucleus and hypothalamic sites. Given the small number of subjects per site, the 
relatively brief testing period $(30 \mathrm{~min})$, and the variability of their results, it seems reasonable to conclude that they made a classic Type II statistical error. They concluded no difference based on small samples of behavior and then generalized that conclusion to an even broader domain. Under naloxone, it can be demonstrated that press rates are reduced. This basic fact is subject to a variety of interpretations, but the demonstrations of reductions are clear (Belluzzi \& Stein, 1977; this work).

Among the issues concerning interpretation of the result that naloxone reduces pressing for ICS is the specificity of the effect. For any effect evidenced by a decrease in leverpress rates, there is the possibility that the effect may be nonspecific, the result of nausea or general malaise produced by the drug rather than a true change in the reward value of the stimulation. Naloxone may produce some nausea in rats, since it has been shown to produce a conditioned taste aversion (LeBlanc \& Cappell, 1975; Stolerman, Pilcher, \& D'Mello, 1978; Van der Kooy $\&$ Phillips, 1977). The reduction in press rates could be due to other nonspecific effects such as naloxone producing increased interference due to more seizurelike activity (Pinsky, Labella, Havlicek, \& Dua, 1978) or increasing negative concomitants accompanying the typically positive ICS (Sparber \& Colelli, 1978).

Stein has recently reported that naloxone increases pressing for escape from imposed ICS while decreasing pressing for ICS by the same rat during alternating 5-min periods (Stein, 1978). This result shows that all press rates are not reduced by naloxone, but does not provide clear evidence of specificity of the naloxone effect. As usual, further research is needed to clarify whether naloxone's effect on pressing for ICS is a side effect, a direct effect on elements of intracranial reward, or an indirect but meaningful effect with respect to reward functions. Regardless of whether naloxone's suppression of ICS is specific or nonspecific, the demonstration of this effect has clear implications for similar studies using naloxone as a pharmacological tool (e.g., Lorens \& Sainati, 1978; Wauquier, Niemegeers, \& Lal, 1974). Naloxone is not an inactive substance in self-stimulation tests.

\section{REFERENCE NOTES}

1. Stein, L., \& Belluzzi, J. D. Personal communication, April 24, 1979.

2. Steiner, S. S., \& Ellman, S. J. Opiate specificity and selfstimulation. Paper presented at Eastern Psychological Association meeting, Philadelphia, Pennsylvania, April 18, 1979.

3. Lind, M. D., Stapleton, J. M., Merriman, V. J., \& Reid, L. D. Addictive agents and intracranical stimulation: Small doses of morphine and tests of their affective consequences. Manuscript in preparation, 1979.

4. Cruz-Morales, S. E., \& Reid, L. D. Addictive agents and intracranial stimulation (ICS): Morphine, naloxone and pressing for amygdaolid ICS. Manuscript in preparation, 1979.

\section{REFERENCES}

Adams, W. J., Lorens, S. A., \& Mitchell, C. L. Morphine enhances lateral hypothalamic self-stimulation in the rat.

Proceedings of the Society for Experimental Biology and Medicine, 1972, 140, 770-771.

BECKER, B. M. Reactivity to intracranial stimulation before and after morphine dependence. Unpublished Master's thesis, Bradley University, 1977.

Belluzzi, J. D., \& Stein, L. Enkephalin may mediate euphoria and drive-reduction reward. Nature, 1977, 266, 556-558.

Bozarth, M. A., \& Reid, L. D. Addictive agents and intracranial stimulation (ICS): Naloxone blocks morphine's acceleration of pressing for ICS. Bulletin of the Psychonomic Society, 1977, 10, 478-480.

Bush, H. D., Bush, M. F., Miller, M. A., \& Reid, L. D. Addictive agents and intracranial stimulation: Daily morphine and lateral hypothalamic self-stimulation. Physiological Psychology, 1976, 4, 79-85.

D'Amour, F. E., \& Sмiтh, D. L. A method for determining loss of pain sensation. Journal of Pharmacology and Experimental Therapeutics, 1941, 72, 74-79.

Esposito, R. V., \& Kornetsky, C. Opioids and rewarding brain stimulation. Neuroscience and Biobehavioral Reviews, 1978, 2, 115-122.

Frederickson, R. C. A. Enkephalin pentapeptides-A review of current evidence for a physiological role in vertebrate neurotransmission. Life Sciences, 1977, 21, 23-42.

Goldstein, A. Opiate receptors and opioid peptides: A ten-year overview. In M. A. Lipton, A. DiMascio, \& K. F. Killam (Eds.), Psychopharmacology: A generation of progress. New York: Raven Press, 1978.

Goldste in, A., \& Cox, B. M. Opiate receptors and their endogenous ligands (endorphins). In F. E. Hahn, H. Kersten, W. Kersten, \& W. Szybalski (Eds.), Progress in molecular and subcellular biology (Vol. 6). New York: Springer-Verlag, 1978.

Goldstein, J. M., \& Malick, J. B. Effect of substance P on medial forebrain bundle self-stimulation in rats following intracerebral administration. Pharmacology, Biochemistry and Behavior, 1977, 7, 475-478.

Hayes, R., Price, D. D., \& Dubner, R. Naloxone antagonism as evidence for narcotic mechanisms. Science, 1977, 196, 600.

Holtzman, S. G. Comparison of the effects of morphine, pentazocine, cyclazocine and amphetamine on intracranial selfstimulation in the rat. Psychopharmacologia (Berlin), 1976, 46, 223-227.

JafFe, J. H., \& Martin, W. R. Narcotic analgesics and antagonists. In L. S. Goodman \& A. Gilman (Eds.), The pharmacological basis of therapeutics. New York: Macmillan, 1975.

KuHAR, M. J. Opiate receptors: Some anatomical and physiological aspects. Annals of the New York Academy of Sciences, $1978,311,35-48$.

LeBlanc, A. E., \& Cappell, H. Antagonism of morphineinduced aversive conditioning by naloxone. Pharmacology, Biochemistry, and Behavior, 1975, 3, 185-188.

Liebman, J. M., \& Seg AL, D. S. Lithium differentially antagonizes self-stimulation facilitated by morphine and (+)-amphetamine. Nature, 1976, 260, 161-163.

Lorens, S. A. Comparison of the effect of morphine on hypothalamic and medial frontal cortex self-stimulation in the rat. Psychopharmacology, 1976, 48, 217-224.

Lorens, S. A., \& Sainati, S. M. Opiate receptors mediate the excitatory (euphorigenic?) effect of ethanol, chlordiazepoxide and morphine on brain stimulation reward. Society for Neuroscience Abstracts, 1978, 4, 135. (Abstract)

MAGNuson, D. J. Studies of morphine and intracranial stimulation. Unpublished Master's thesis, Bradley University, 1977.

Pert, A. Effects of opiates on rewarding and aversive brain stimulation in the rat. Proceedings of the 37th Annual Scientific Meeting Committee on Problems of Drug Dependence, 1975, 963-973. 
Pinsky, C., LaBella, F. S. Havlicek, V., \& Dua, A. K. Apparent central agonist actions of naloxone in the unrestrained rat. In J. M. Van Ree \& L. Terenius (Eds.), Developments in neuroscience (Vol. 4). New York: Elsevier/North-Holland Biomedical Press, 1978.

REID, L. D., \& Bozarth, M. A. Addictive agents and intracranial stimulation (ICS). Proceedings of Fortieth Annual Scientific Meeting of the Committee on Problems of Drug Dependence, 1978, 729-741.

Sparber, S. B., \& Colelli, B. Footshock mitigates the suppression of operant behavior caused by naloxone in morphine-naive rats. In J. M. Van Ree \& L. Terenius (Eds.), Developments in neuroscience (Vol. 4). New York: Elsevier/ North-Holland Biomedical Press, 1978.

Ste in, L. Brain endorphins: Possible mediators of pleasure and reward. Neurosciences Research Program Bulletin, 1978, 16, 556-573.
Stolerman, I. O., Pilcher, C. W. T., \& D'Mello, G. D. Stereospecific aversive property of narcotic antagonists in morphine-free rats. Life Sciences, 1978, 22, 1755-1762.

Van der Kooy, D., LePiane, F. G., \& Phillips, A. G. Apparent independence of opiate reinforcement and electrical selfstimulation systems in rat brain. Life Sciences, 1977, 20, 981-986.

VAN DER Kooy, D., \& Phillips, A. G. Temporal analysis of naloxone attenuation of morphine-induced taste aversion. Pharmacology, Biochemistry and Behavior, 1977, 6, 637-641.

Wauquier, A., Niemegeers, C. J. E., \& Lal, H. Differential antagonism by naloxone of inhibitory effects of haloperidol and morphine on brain self-stimulation. Psychopharmacologia, 1974, 37, 303-310.

(Received for publication May 17, 1979; revision accepted August 14, 1979) 